\title{
EL FERROCARRIL GRAN OESTE ARGENTINO Y EL BANCO INGLÉS DE INVERSIÓN J. S. MORGAN \& CO., 1887-1897
}

\author{
THE ARGENTINE GREAT WESTERN RAILWAY \\ AND THE BANK J. S. MORGAN \& CO., 1887-1897
}

\author{
Mario Justo López \\ Universidad de Buenos Aires, Buenos Aires, Argentina <mjustolopez@yahoo.com.ar>
}

Resumen. El banco de inversión J. S. Morgan \& Co. tomó el control del Ferrocarril Gran Oeste Argentino para proteger el valor de los títulos de dicha compañía que conservaba en su poder. La crisis de 1890 había puesto en peligro la supervivencia de la empresa de transportes. La consulta de los documentos que se conservan en el archivo del banco, que se encuentra en la Guildhall Library de Londres, permite reconstruir la forma en que ejerció ese control, los pasos seguidos para lograr que la empresa superara los efectos de la crisis y las ventajas que obtuvo respecto de otros inversores por su posición dominante.

Palabras clave: ferrocarriles; infraestructura del transporte; bancos de inversión.

Abstract. The merchant bank J. S. Morgan \& Co. took control of the Argentine Great Western Railway Company to safeguard the shares and debentures value that the bank had purchased before the Baring Crisis of 1890. The research on the files of the Morgan Bank Archive which is kept in the Guildhall Library, London, leads to the reconstruction of the way followed by the bank to take control and get the railway recovered. Also, the documents show how the merchant bank J. S. Morgan \& Co. was put in a more favourable position in relation to other investors in the railway company.

Key words: railways; transport infrastructure; investment Banks.

Fecha de recepción: septiembre de 2013. Fecha de aceptación: noviembre de 2013.

\section{INTRODUCCIÓN}

$\mathrm{E}$ n este trabajo nos proponemos describir la formación y la actividad en los primeros años de una empresa de capitales británicos destinada a explotar un ferrocarril en Argentina. Se trata del caso del ferrocarril Gran Oeste Argentino (GOA), desde su creación en 1887 hasta una época cercana a fines del siglo XIX. Durante este tiempo la empresa

Am. Lat. Hist. Econ., año 21, núm. 3, septiembre-diciembre, 2014, pp. 144-175 
fue controlada, en mayor o menor medida, por el banco de inversión londinense J. S. Morgan \& Co. La reconstrucción de esa vinculación entre una empresa de servicios y una entidad financiera se hará con el mayor detalle posible, a fin de incorporar una gran cantidad de datos y evitar, de esa manera, que las conclusiones a las que llegamos se conviertan en meras afirmaciones insostenibles.

En el relato de los hechos será nuestra pretensión mostrar la forma y las circunstancias en que el banco tomó el control del ferrocarril, cómo lo ejerció durante unos diez años para después desinteresarse de él. En ese relato nos veremos obligados a hacer referencia a la actuación de algunas otras empresas ferroviarias y constructoras de ferrocarriles, a decisiones tomadas por el gobierno argentino, a mencionar los efectos de la grave crisis económica que afectó a Argentina en 1890 y años posteriores y a entrar a considerar, brevemente, la cuestión de la aplicación del mecanismo de las garantías de beneficio mínimo que funcionó hasta esa crisis como incentivo para la inversión de capitales en la actividad ferroviaria. En la parte final del trabajo se incluirán algunas conclusiones extraídas del caso descrito y su comparación con otros casos de formación y actuación de empresas ferroviarias de capital británico.

En nuestra opinión, el caso del Gran Oeste Argentino y su relación con el banco J. S. Morgan \& Co. parece, en principio, una excepción. Es difícil, si no imposible, encontrar otra compañía ferroviaria de capital británico en Argentina en la que el agente financiero que participó de su formación haya ejercido posterior control en su manejo. La excepcionalidad, no obstante, si se profundiza en ella y se presta atención a las razones por las cuales el agente financiero mantuvo sometida la voluntad de la empresa de servicios, muestra que los parámetros seguidos al volcar capitales a la actividad ferroviaria no fueron, en definitiva, muy diferentes a los de los otros casos. Sobre todo ello se reflexionará en las conclusiones. Estas también incluirán un intento de sintetizar el procedimiento de actuación de los bancos de inversión en la creación de empresas ferroviarias y determinar cuáles eran sus objetivos.

En la investigación que precedió a la redacción de este trabajo la atención fue puesta, en especial, en el archivo de la casa bancaria J. S. Morgan \& Co. que se encuentra en la Biblioteca Guildhall de Londres. Además se consultaron otras fuentes primarias en archivos de Londres y de Buenos Aires y se buscó información en temas no centrales en la bibliografía especializada. 


\section{LA VENTA DEL FERROCARRIL ANDINO \\ y LA CREACión del Gran Oeste Argentino}

La empresa Gran Oeste Argentino fue creada para adquirir una línea ferroviaria ya existente. Corresponde, entonces, ocuparse de ella para entender el surgimiento de la nueva empresa. Entre 1881 y 1885 el gobierno federal argentino había construido por administración las secciones entre Villa Mercedes (provincia de San Luis), Mendoza (capital de la provincia del mismo nombre) y San Juan (también capital de la provincia homónima), como prolongaciones del denominado Ferrocarril Andino, que se desprendía como un ramal del Ferrocarril Central Argentino en la estación Villa María (provincia de Córdoba) y de allí se extendía a Río Cuarto y Villa Mercedes. En 1885 habían sido habilitados los servicios hasta Mendoza y San Juan (véase mapa 1). Cuando Miguel Juárez Celman asumió la presidencia de Argentina en octubre de 1886, inmediatamente puso de manifiesto su intención de vender los ferrocarriles de propiedad del Estado federal y la primera venta que llevó a cabo fue la de las secciones entre Villa Mercedes y San Juan. Ello fue debido a que era la venta que requería menos trámites previos. Invocando una ley anterior y un contrato de concesión de 1878, el presidente consideró que no necesitaba autorización del Congreso de diputados y senadores para ceder esa línea a sus concesionarios originales, anteriores a la construcción estatal, los hermanos chilenos Juan Eduardo y Mateo Clark, debiendo estos entregar al Estado a cambio todo lo que este había gastado para erigir lo que se cedía.

El contrato de venta con los hermanos Clark se firmó el 21 de enero de 1887. El precio se fijó en 12312000 pesos, debiendo abonarse 2000000 de pesos al ser aprobado el contrato por el gobierno y, luego, cada 30 días 1000000 de pesos hasta completar el total. ${ }^{1}$ Los Clark eran típicos intermediarios de la época: en 1874 habían firmado un contrato de concesión con el gobierno argentino para construir un ferrocarril de Buenos Aires a Chile, pero en 1878, mediante nuevo contrato, se obligaron a construir primero la sección entre Buenos Aires y Villa Mercedes, San Luis, permitiendo que el Estado iniciara la construcción del resto (López, 1991). Con conexiones locales, negociaban y discutían con los sucesivos gobiernos, de los que obtenían concesiones, y luego llevaban el negocio a Londres, donde la experiencia indicaba que había capitalistas dispuestos a invertir en Argentina. Los Clark también eran empresarios constructores. No se limitaban a ceder la concesión por un precio a la compañía que se consti-

\footnotetext{
${ }^{1}$ Las monedas se citan de acuerdo con los documentos de los que proviene la información. Téngase en cuenta que, aproximadamente, cinco pesos oro sellado (pesos) eran equivalentes a una libra esterlina y que una libra de fines del siglo XIX representa, al menos, 100 libras de 2013.
} 


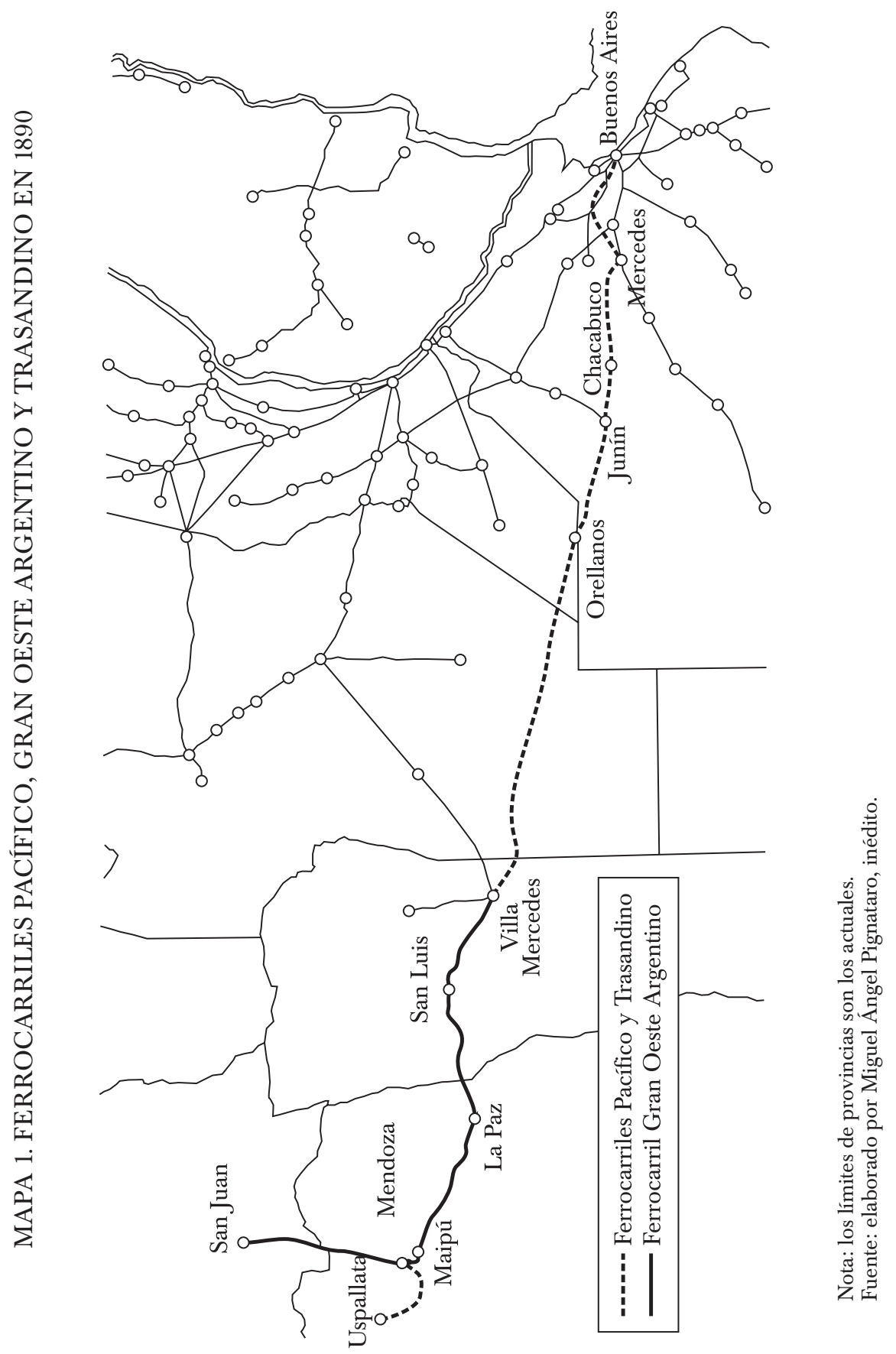


tuía al efecto en Londres sino que, además, contrataban con ella las obras necesarias para poner en marcha el proyecto. Los hermanos se habían dividido el trabajo al respecto. Mateo residía en Londres y negociaba con los capitalistas. Juan Eduardo se quedaba en Buenos Aires y se ocupaba de organizar los trabajos, subcontratando, y de tratar con las autoridades. En 1883 habían puesto en marcha una empresa, el Ferrocarril Buenos Aires al Pacífico (FBAP), que cubría el trayecto entre Mercedes (provincia de Buenos Aires) y Villa Mercedes (San Luis), inaugurado en forma íntegra a fines de 1886. Para entonces los Clark, por su forma poco clara de actuar, habían entrado en conflicto con la compañía del FBAP y habían comprometido todas las relaciones forjadas en Londres hasta el momento. Es por esa razón que, por la decisión del presidente Juárez Celman, al presentárseles la oportunidad de la compra de una parte del Ferrocarril Andino no pudieron recurrir a las vinculaciones hechas con anterioridad ni a los agentes financieros que ayudaron a crear el FBAP, fundamentalmente la casa bancaria de Londres C. de Murrieta.

Sin embargo, en la búsqueda de nuevos contactos, los Clark encontraron pronto ayuda en la casa comercial de Buenos Aires Samuel B. Hale y Cía. y, en particular, en uno de sus miembros, Charles Henry Sanford, partícipe imprescindible por su relación con el gobierno argentino y su implicancia en los hechos que llevaron a la crisis de 1890 (López, 2000), quien era su representante en la capital británica. Fue por medio de este último que la casa bancaria J. S. Morgan \& Co. pudo ser interesada en el asunto. Desde comienzos de 1884 Sanford había iniciado sus contactos con este banco. ${ }^{2}$ Con la intervención de J. S. Morgan \& Co., el negocio de los Clark se encarriló y estos pudieron cumplir con el contrato que ya habían firmado con el gobierno y pagar, en menos de un año, la importante suma de dinero a la que se habían obligado. Para lograrlo debieron cumplir tres pasos en los que fue fundamental la presencia de J. S. Morgan \& Co.: a) la constitución en Londres de una nueva empresa, que se denominó Argentine Great Western Railway Co. Ltd. (Ferrocarril Gran Oeste Argentino); b) la cesión del contrato de compra del Ferrocarril Andino por parte de los concesionarios a la nueva empresa, y $c$ ) la conformación del sindicato de bancos para obtener el capital necesario negociando los títulos de la nueva compañía y de esa manera pagar el precio al gobierno y poner en marcha a la empresa.

2 (9 de febrero de 1884). Morgan Grenfell Papers (Correspondencia de J. S. Morgan \& Co. con Sanford y Hale, leg. 21760.H.C.4.1.4). Guildhall Library. Londres, Inglaterra. Del mismo archivo, consultar la correspondencia del 14 de junio de 1884, 16 de marzo de 1885 y 20 de mayo de 1886 . 
El primer paso se concretó, formalmente el 29 de abril de 1887, al registrarse en la capital del Reino Unido la Argentine Great Western Railway Co. Ltd. con un capital autorizado de 1000000 de libras esterlinas en 50000 acciones de 20 libras cada una y con autorización para emitir debentures ${ }^{3}$ hasta por 2370000 libras. Su objeto era adquirir de Juan Eduardo Clark o Mateo Clark el ferrocarril de Villa Mercedes a San Juan construido por el gobierno argentino. El directorio quedó integrado por George Russell, Mateo Clark, George Cooper, C. N. Lawrence, Frederick William Lawrence, miembro de J. S. Morgan \& Co., O. C. Waterfield y E. Zimmermann. Los abogados de la nueva compañía fueron, desde el inicio, Norton, Rose y Norton. ${ }^{4}$

El segundo paso se llevó a cabo mediante el contrato del 26 de mayo de 1887, entre la compañía recién constituida y los hermanos Clark. Estos transfirieron la línea recientemente adquirida al gobierno y se obligaron a dejar un capital de trabajo de 25000 libras. También contrataron con la nueva empresa las reparaciones y mejoras cuya necesidad surgía de informes anteriores y la construcción de una nueva estación en Villa Mercedes, obras cuyo valor se fijaba en 100000 libras, y en pago de todo ello la compañía adquirente entregaba 3370000 libras de la siguiente forma: 500000 libras en acciones preferidas con derecho a un dividendo de 5\% acumulativo; 500000 libras en acciones ordinarias, y 2370000 libras en bonos con interés de 5\% anual. Las acciones preferidas y los bonos serían entregados a medida que fueran venciendo los plazos de pago acordados por el gobierno argentino y las acciones ordinarias una vez que el gobierno argentino aprobara la transferencia. Los títulos podían ser vendidos a solicitud de los Clark, pedido que necesariamente iba a ocurrir. Los bonos podían negociarse por un precio no inferior a $90 \%$ y las preferidas no menor a 80\%. La compañía designaba al ingeniero William Roberts para certificar las obras valuadas en 100000 libras. ${ }^{5}$ Hasta aquí, y si todo salía como estaba planeado, la operación constituía un buen negocio para los intermediarios. El precio comprometido con el gobierno, de 12312000 pesos, equivalía a 2460000 libras, aproximadamente. Lo obtenido por la venta al Gran Oeste Argentino podía llegar a 2408000 libras en efectivo (vendiendo las acciones preferidas a 80\%, los debentures a 90\%, gastando 100000 libras en las obras y reservando 25000 libras para capital de trabajo) y 500000 libras en acciones ordinarias. El valor de estas era incierto, pero, conservándolas en su poder y comenzando a funcionar la empresa,

${ }^{3}$ Debentures era el nombre que se daba entonces a los bonos.

${ }^{4}$ (1887). Public Record Office (Dissolved Companies, compañía núm. 24345, Gran Oeste Argentino, caja 36158). Board of Trade 31. Londres, Inglaterra.

${ }_{5}^{5}$ (1887). Public Record Office (Dissolved Companies, compañía núm. 24345, Gran Oeste Argentino, caja 36158). Board of Trade 31. Londres, Inglaterra. 
podía obtenerse por ellas entre 300000 y 350000 libras. Sin embargo, las cosas no salieron como los Clark habían previsto.

J. S. Morgan \& Co. había intervenido en el primer paso, tanto es así que en el directorio ocupaba un lugar el socio menor de la firma Frederick William Lawrence, socio menor (junior working partner) y su presidente era George Russell, también vinculado a la casa, según Burk (1989). Pero donde el banco desarrolló ampliamente sus aptitudes fue en la colocación de los títulos emitidos por la nueva compañía ferroviaria en el mercado de Londres, a fin de obtener el efectivo con el cual pagar al gobierno argentino. Para ello, como era usual, J. S. Morgan \& Co. formó un sindicato y suscribió diversos convenios. En el sindicato ingresaron los bancos de inversión más importantes, obligándose cada uno a suscribir determinada cantidad de títulos. El mayor compromiso fue el del propio J. S. Morgan \& Co. y el de Baring Brothers \& Co., ambos con 500000 libras; luego los seguía C. J. Hambro \& Co. con 400000 libras; las casas vinculadas a J. S. Morgan \& Co. (Drexel Morgan de Nueva York y Drexel Harjes de París) asumieron la colocación de otras 400000 libras; el influyente Charles Henry Sanford se anotó con 30000 libras, Anthony Gibbs \& Sons. se obligó por 100000 libras, el banco Société Genérale de París hizo lo mismo por 50000 libras, Greenwood \& Co. (la firma de Alexander Henderson) también decidió comprometerse por 50000 libras. ${ }^{6} \mathrm{El}$ sindicato convino con los Clark en adquirir los debentures a $90 \%$ de su valor nominal y las acciones preferidas a $85 \%$ del mismo, pero logró colocarlos en el mercado a 96.5 y $100 \%$, respectivamente. Por esa sola operación obtuvo una ganancia de aproximadamente 180000 libras que se repartió entre sus miembros en proporción al compromiso asumido. J. S. Morgan \& Co. y sus asociados se llevaron 64150 libras por su parte en el sindicato, además de la comisión de $1 \%$ sobre el valor nominal de los valores, es decir 28700 libras. ${ }^{7}$ Es cierto que durante un tiempo, aunque breve, los miembros del sindicato tuvieron que hacer un adelanto de dinero a los Clark mientras iban percibiendo las cuotas de los suscriptores finales de los títulos que terminaron de ser pagadas el 1 de septiembre de $1887^{8}$

${ }^{6}$ Morgan Grenfell Papers (leg. 21775, vol. 4, f. 239). Guildhall Library. Londres, Inglaterra.

${ }^{7}$ Morgan Grenfell Papers (leg. 21777, vol. 4, fs. 100 y 105). Guildhall Library. Londres, Inglaterra. Véase también (26 de mayo de 1887). Prospectus Argentine Western Railway original en la Guildhall Library. Hay una fotocopia en la Fundación Museo Ferroviario, Buenos Aires. Los prospecti eran folletos que se hacían circular para información de los posibles inversores cuando se colocaban títulos en el mercado de Londres.

${ }^{8}$ Es interesante observar cómo en la instalación de una nueva empresa necesariamente se producía sobrecapitalización. En este caso ni el valor representado por las acciones ordinarias, que eran la comisión del intermediario, ni 100\% de los demás títulos, que eran negociados muy bajo a la par por los bancos de inversión, se traducían en inversiones reales. A pesar de ello, por lo menos hasta 1906, el gobierno argentino siguió insistiendo en su política de atraer nuevos in- 
J. S. Morgan \& Co. estaba haciendo un buen negocio. Había convertido en realidad la operación iniciada por los Clark y estaban obteniendo importantes ganancias. Además, el 30 de junio de 1887 había suscrito con la nueva compañía del Gran Oeste Argentino un contrato por el cual el banco se convertía en su agente financiero. Por el pago de dividendos e intereses a los tenedores de títulos actuales o futuros se fijaba una comisión de 1\%; para el rescate de títulos, si este se llevaba a cabo, la comisión sería de 0.5 por ciento. ${ }^{9}$

Sin embargo, como era usual en la época y como también resultaba de la propia esencia del banco de inversión, J. S. Morgan \& Co. y sus allegados no se conformaron con la ganancia proveniente del sindicato y de las comisiones, sino que buscaron beneficios adicionales en la especulación con la suba de los títulos de la nueva empresa. En líneas generales, dicha especulación se llevó a cabo de la siguiente forma: se compraron debentures con la finalidad de venderlos a corto plazo, a lo sumo al año siguiente; se compraron acciones preferidas para retenerlas en cartera un tiempo mayor; se compraron, por último, 5000 acciones ordinarias a los Clark por un precio muy bajo, probablemente porque los chilenos necesitaban efectivo. Los debentures tenían pactada una tasa de interés de 5\% anual. Dada la tasa vigente en el mercado de Londres, que era inferior, si la empresa se afirmaba, a corto plazo los debentures debían subir algunos puntos, por encima de la par. En consecuencia, lo recomendable era esperar un corto tiempo y desprenderse de estos títulos. Las acciones preferidas, en cambio, para que su dividendo privilegiado se abonara, necesitaban que la línea férrea produjera utilidades, lo que requería de más tiempo para saberlo. Pero si ello ocurría los dividendos garantizados también eran superiores al interés de plaza y así llevarían el precio de cotización más arriba que la par. Por otra parte, las acciones daban derecho a participar en el manejo de la empresa y eso podía ser útil para, llegado el caso, proteger la propia inversión. La inversión en acciones ordinarias era altamente especulativa, pues para que las mismas percibieran dividendos saldados, los de las preferidas, era necesario una empresa en pleno funcionamiento y altamente rentable. Lograr eso podía llevar algunos años, como lo demostraba la experiencia. En concreto, J. S. Morgan \& Co. adquirió unas 150000 libras en debentures en junio de 1887 y se desprendió de una gran parte entre junio y noviembre de 1888; pero no obtuvo una gran ganancia pues los precios de venta fueron de 95 a 98 libras. Drexel \& Co. adquirió 25000 libras con

versores para hacer competencia a las empresas establecidas cuando estas, que no necesitaban ni de agentes financieros ni de intermediarios, podían invertir en forma más eficiente.

${ }_{9}$ (30 de junio de 1887). Morgan Grenfell Papers (Contrato, leg. 21760.H.C.4.1.7). Guildhall Library, Londres, Inglaterra. 
el mismo tipo de título en julio de 1887 y vendió la mayor parte en agosto de 1888. Lo mismo hizo el socio Robert Gordon, y un hermano del otro socio W. H. Burns. ${ }^{10}$ Respecto de las acciones preferidas, desde un primer momento todo el grupo -J. S. Morgan \& Co., las casas allegadas y algunos socios- acumuló 8000 acciones, por un valor nominal de 160000 libras y, a pesar de algunas compraventas, mantuvieron esa cantidad en cartera. Lo mismo ocurrió con las ordinarias. ${ }^{11}$

\section{J. S. Morgan \& Co. Participa de la dirección DEL Gran Oeste ARgentino}

Desde su fundación, J. S. Morgan \& Co. tuvo una importante presencia en la conducción del Gran Oeste Argentino. Prueba de ello es una copiosa correspondencia entre el banco londinense, sus representantes en Buenos Aires y miembros del gobierno argentino, de la que resulta que, en muchos casos, el banco desplazaba al mismo directorio en la toma de decisiones. Así, en carta del 2 de diciembre de 1887 dirigida a Nicholas Bouwer, director local del Gran Oeste Argentino, J. S. Morgan \& Co. se refiere a este como "nuestra compañía". ${ }^{12}$ Los temas en los que la voluntad del agente financiero se convertía en decisión de la empresa fueron amplios, desde el conflicto inevitable con los hermanos Clark, tanto como empresarios de las obras de mejora como constructores del vecino Trasandino, la competencia con el vecino FBAP, hasta el conflicto con el gobierno por el pago de la garantía y la necesidad de mejorar el servicio.

Los hermanos Clark mantuvieron por un tiempo una estrecha relación con el Gran Oeste Argentino. Habían conservado una gran cantidad de acciones, por lo menos 2500 preferidas y 20000 ordinarias. ${ }^{13}$ Mateo Clark

${ }^{10}$ Para datos sobre la compraventa de debentures, véase Morgan Grenfell Papers (leg. 21769, vols. 24 y 25; leg. 21777, vol. 4, f. 101; leg. 21778, vol. 5, f. 65). Guildhall Library. Londres, Inglaterra.

${ }^{11}$ La primera lista de accionistas del 8 de junio de 1887 presenta las siguientes tenencias: J. S. Morgan \& Co., 2930 acciones preferidas; Drexel Harjes, 300; Robert Gordon, 1 500; W. H. Burns, 1 000; F. W. Lawrence, 500; J. Harjes, 490; John Pierpont Morgan, 890; Anthony Drexel, 880. En ese sentido este grupo era el mayor tenedor de acciones preferidas. Lo seguía Mateo Clark con 2 500. Véase (1887). Public Record Office (Dissolved Companies, compañía núm. 24345, Gran Oeste Argentino, caja 36158). Board of Trade 31. Londres, Inglaterra. Las acciones de F. W. Lawrence fueron adquiridas por J. S. Morgan \& Co. y entregadas a él como salario adicional. Véase Morgan Grenfell Papers (leg. 21768, vol. 7). Guildhall Library, Londres, Inglaterra.

${ }^{12}$ Morgan Grenfell Papers (leg. 21795, vol. 4, f. 287). Guildhall Library. Londres, Inglaterra.

${ }^{13}$ (1887). Public Record Office (Dissolved Companies, compañía núm. 24345, Gran Oeste Argentino, caja 36158). Board of Trade 31. Londres, Inglaterra. El valor de estos títulos, como dijimos en el texto, todavía era incierto, hasta tanto el ferrocarril comenzara a dar utilidades. Realmente no está claro por qué J. S. Morgan \& Co. recibió 5000 de ellos, si fue por pedido de Clark a fin de obtener efectivo o si fue una comisión más por su actuación. En junio los Clark entregaron 
fue designado miembro del directorio desde el comienzo y perduró en él hasta 1891. Juan Eduardo Clark dirigía en Argentina las obras contratadas por un valor de 100000 libras. Sin embargo, la relación, poco a poco, comenzó a deteriorase, lo que no era de extrañar dados los antecedentes de los empresarios chilenos. ${ }^{14} \mathrm{El}$ primer problema que surgió, ya en diciembre de 1887, fue con motivo del uso de las instalaciones de Mendoza por parte de los constructores del Ferrocarril Trasandino, que no eran otros que los mismos Clark; el segundo fue una discusión en torno al valor de las mejoras ejecutadas y su forma de pago, lo que llevó a la necesidad de redactar un convenio adicional, que tampoco sirvió para mucho; el tercero, el más grave, fue el hecho de que Juan Eduardo Clark, esta vez asociado con Sanford, resultara adjudicatario de la venta del remanente del Andino, que podía considerarse parte de la misma línea. En este caso Sanford tuvo éxito en convencer a J. S. Morgan \& Co. de que su intervención tenía como propósito beneficiar al GOA y no montar un negocio aparte, de tal modo que mantuvo la confianza en él por un tiempo mayor que los chilenos. ${ }^{15}$ En todas estas cuestiones J. S. Morgan \& Co., fundamentalmente a través de W. H. Burns o de Robert Gordon, actuaba representando al ferrocarril, sin mencionar siquiera que consultaba con el directorio.

La rivalidad con el FBAP había nacido con el Gran Oeste Argentino mismo. Su línea, prolongación natural de la del FBAP y parte de una misma concesión originaria, había ido a parar a una compañía diferente porque los Clark estaban en conflicto con este último. Es razonable que el FBAP considerara al GOA como un intruso. Con motivo del intento de venta por el Estado nacional del remanente del Andino la rivalidad se puso de manifiesto. El FBAP, que no quería dejar fortalecer la posición del recién llegado, al parecer ofreció comprar ese remanente por 6700000 pesos. J. S. Morgan \& Co., en esa circunstancia, como gestor del GOA, consultó con directores del vecino Central Argentino la posibilidad de asociarse para impedir esa compra y tomar ellos el control de la línea de Villa María a Villa Mercedes. Es en ese momento cuando Sanford se interpuso y, junto con Clark, adquirió la línea por 7395000 pesos, alegando que lo hacía para contrarrestar la oferta del FBAP, ambos firmaron el contrato de compra por el remanente del Andino en febrero de 1888. Más adelante

3500 acciones más a otras personas vinculadas a la operación (entre ellos F. W. Lawrence, C. H. Sanford, Robert Gordon, W. H. Burns y W. C. Burns) pero más adelante las recuperaron. Véase la misma fuente anterior.

${ }^{14}$ Los chilenos, por estos años, habían seguido adquiriendo concesiones y contratando obras para ferrocarriles en la Argentina. Sin embargo, fueron extremadamente desprolijos en su actuación, lo que contribuyó a generar conflictos y a caer en la insolvencia en 1891.

${ }^{15}$ Morgan Grenfell Papers (leg. 21795, vol. 4, fs. 287, 304 y 467). Guildhall Library. Londres, Inglaterra. 
ambos intentaron transferir la línea al Central Argentino pero, finalmente, como no cumplieron las cláusulas de la compra, el gobierno rescindió toda la operación y conservó al ferrocarril en su poder (López, 2000). ${ }^{16}$ La disputa por el remanente del Ferrocarril Andino era razonable en la situación de competencia en que algunas empresas ferroviarias se habían colocado en la segunda mitad de la década de 1880. El FBAP, si compraba la línea estatal, podía "bloquear" al GOA el acceso a los puertos e imponerle tarifas ventajosas para él; el Central Argentino, en el mismo caso, podía perder el tráfico de Cuyo a manos del FBAP; el GOA necesitaba que la vía del Andino fuera de él o de un tercero, como el Central Argentino, pero no del FBAP, si quería poder elegir como destino de los productos de Cuyo (región formada por San Luis, Mendoza y San Juan) los puertos de Buenos Aires o de Rosario. En definitiva, frustrada la venta del Andino poco después, por incumplimiento de Clark y Sanford, el GOA pudo mantener tarifas razonables hasta puerto para los productores de Mendoza y San Juan usando, alternativamente, al Central Argentino o al FBAP. En todas estas discusiones J. S. Morgan \& Co. defendió directamente los intereses del Gran Oeste Argentino.

\section{EL CONFLICTO POR LA SANCIÓN DE LA LEY 2379}

Pero el tema más delicado en el cual los agentes financieros gestionaron la defensa de los intereses de la compañía ferroviaria fue el conflicto suscitado con el gobierno argentino. Este, ya a fines de 1887, imputó al Gran Oeste Argentino no prestar un servicio adecuado por falta de material rodante. El ferrocarril, por su parte, se quejaba de la falta de pago puntual de la garantía acordada; entre otras cosas, dichas garantías fueron otorgadas hasta 1890 como incentivo para la inversión en ferrocarriles (López, 2000). Parece indiscutible que el material rodante de la línea era insuficiente y ello era producto, en parte, de que al adquirirse el gobierno retuvo locomotoras y vagones para destinarlos al remanente que no se vendía y que habían sido adquiridos para la prolongación a Cuyo. Ello había sido pactado expresamente en el contrato de compra firmado por Juan Eduardo Clark, cuyo artículo séptimo estipulaba que este dejaría

sin cargo para el gobierno, 16 locomotoras, o sea más del doble de las que dicha línea tenía al empezarse la construcción de la prolongación, y un número de coches, vagones y furgones igual al que existía en ella en la misma época, reservándose el

\footnotetext{
${ }^{16}$ Morgan Grenfell Papers (leg. 21795, vol. 4, fs. 317-319; leg. 21802, vol. 6, f. 1). Guildhall Library. Londres, Inglaterra.
} 
gobierno el derecho de tomar hasta una tercera parte del tren rodante, abonando por el exceso el precio que pagase Clark (República Argentina, Ministerio de Obras Públicas, 1902, p. 101).

Esta cláusula nunca fue aceptada por J. S. Morgan \& Co., probablemente porque los Clark le ocultaron su verdadero alcance. Por otra parte, el material rodante entregado no estaba en buenas condiciones. De las 41 locomotoras que transfirió el Andino debieron ser reparadas inmediatamente 31 (López, 2000). La cuestión del material rodante generó sucesivas fricciones entre el GOA y el gobierno, con acusaciones recíprocas de incumplimiento de las obligaciones contraídas.

El Gran Oeste Argentino, como antes dijimos, había designado a William Roberts como su ingeniero con la función de controlar las obras contratadas con los hermanos Clark. Pronto, cuando los Clark hicieron entrega de la línea en octubre de 1887, Roberts se convirtió en gerente general. Con base en un relevamiento sugirió tomar una serie de medidas para mejorar el servicio, fundamentalmente la compra de locomotoras y vagones. ${ }^{17}$ Mientras ello ocurría, J. S. Morgan \& Co., preocupado por el éxito de la inversión, insistía a través de Nicholas Bouwer que el gobierno fijara con precisión las fechas de pago de la garantía la que, dados los primeros resultados de la explotación, era esencial para poder cumplir con las obligaciones financieras. J. S. Morgan \& Co. pedía que esas fechas fueran el 1 de marzo y el 1 de noviembre de cada año. ${ }^{18}$ Sin embargo, el gobierno de Juárez Celman, dentro de su política oscilante, comenzaba ya a mostrar desilusión frente al comportamiento de las empresas privadas y pensaba tomar alguna medida coercitiva para obligarlas a mejorar el servicio. En mayo de 1888 Juárez Celman, en su mensaje al Congreso, decía que no había ninguna empresa que "tome en cuenta sus verdaderas obligaciones para con el público" (Mabragaña, ca. 1910, pp. 219-220); en julio de dicho año se sancionó la Ley 2274 que creó la Dirección de Ferrocarriles Nacionales con el propósito, entre otros, de controlar el desempeño de los concesionarios de ferrocarriles y, sobre todo, en octubre, también de 1888, se sancionó la Ley 2379 que disponía la suspensión del pago de la garantía "a toda empresa que no conservara en buen estado y en cantidad suficiente al tren rodante de acuerdo con lo que determinara la autoridad competente" (pp. 219-220). Por la misma norma también se autorizaba al

${ }^{17}$ (30 de junio de 1888). Annual Reports. Gran Oeste Argentino, Londres, Inglaterra. El directorio resolvió comprar cuatro locomotoras y, poco después, dos más, además de vagones para hacienda, sin perjuicio de continuar con las reparaciones de lo recibido. Véase Morgan Grenfell Papers (leg. 21795, vol. 4, fs. 304 y 402). Guildhall Library, Londres, Inglaterra.

${ }_{18}$ (3 de febrero de 1888). Morgan Grenfell Papers (leg. 21795, vol. 4, f. 327). Guildhall Library, Londres, Inglaterra. 
poder ejecutivo a "invertir el valor de la garantía devengada y retenida [...] en la adquisición del tren rodante necesario para colocar a la línea respectiva en las condiciones de ley" (pp. 219-220). La ley era consecuencia de un proyecto iniciado en la Cámara de Diputados a raíz de quejas por el servicio del Gran Oeste Argentino (López, 2000). ${ }^{19}$

La sanción de la Ley 2379 provocó la airada reacción de J. S. Morgan \& Co., en términos tales que muestran el alto interés que la casa tenía en relación con el Gran Oeste Argentino y, también, la arrogancia y falta de tacto de sus socios. Por telegrama del 18 de octubre de 1888, dirigido directamente al vicepresidente de la república, Carlos Pellegrini, la casa bancaria protestaba por la posible aplicación de la ley al ferrocarril y amenazaba con tomar medidas que serían "desastrosas para el crédito argentino en Europa" ${ }^{20}$ La respuesta no se hizo esperar. Cuatro días después Pellegrini sostuvo que el pago de la garantía se justificaba sólo en la medida en que el ferrocarril cumpliera bien el servicio. Entre otras cosas decía que "el gobierno tiene el derecho de defender el interés público contra compañías irrespetuosas". ${ }^{21}$ Finalmente Pellegrini proponía una fórmula de acuerdo sugiriendo a J. S. Morgan \& Co. que usara su influencia para obligar al GOA a adquirir material rodante y él usaría la suya para que el gobierno no actuara inmediatamente. J. S. Morgan \& Co. aceptó la sugerencia y en telegrama del 29 de octubre de 1888 se comprometió a que el ferrocarril adquiriera todo el material rodante necesario para poner la línea en perfecto funcionamiento. Pidió el plazo de un año para completar la incorporación, por necesidades de los fabricantes, y se comprometió a adelantar el dinero necesario mientras los nuevos títulos a emitir para reunir capital eran colocados en el mercado. ${ }^{22}$

La discusión con el gobierno argentino había colocado al banco londinense prácticamente como administrador del ferrocarril. Él había discutido, alcanzado un acuerdo y asumido el compromiso de financiar las adquisiciones de locomotoras y coches. Llegado el momento de concretar las medidas para obtener capital fue el banco el que impuso al directorio el curso de acción a seguir. Se estimaba que sería necesario reunir hasta 220000 libras. Para ello se resolvió emitir nuevos debentures por 250000

${ }^{19}$ Las oscilaciones de la política ferroviaria de Juárez Celman que se mencionan en el texto se comprueban por el hecho de que, mientras dictaba medidas restrictivas, la Ley 2265 de junio de 1888 establecía un mecanismo de pago de las garantías más favorable a las empresas.

${ }^{20}$ Morgan Grenfell Papers (leg. 21802, vol. 6, f. 33). Guildhall Library. Londres, Inglaterra. Entre los fundamentos de su protesta J. S. Morgan \& Co. decía que no podían cambiarse las condiciones de la concesión dada a Clark y que el gobierno se había llevado material rodante por un valor de 40000 libras sin haberlo pagado.

${ }^{21}$ Morgan Grenfell Papers (leg. 21802, vol. 6, f. 34). Guildhall Library. Londres, Inglaterra. Inglaterra.

${ }^{22}$ Morgan Grenfell Papers (leg. 21802, vol. 6, fs. 35 y 36). Guildhall Library. Londres, 
libras a $4.5 \%$ de interés que J. S. Morgan \& Co. tomaría a 75\% de su valor nominal entregando las sumas a partir de enero de 1889 a razón de 30000 libras de inmediato, 60000 libras en febrero, 70000 libras en marzo, 40000 libras en abril, 30000 libras en mayo y 20000 libras en junio. Al mismo tiempo el banco advertía al directorio que debía cubrir los gastos con los ingresos. ${ }^{23} \mathrm{~J}$. S. Morgan \& Co. cumplió con sus entregas de dinero en fecha y, para la colocación de los títulos, formó, como de costumbre, un sindicato y colocó buena parte de ellos entre sus clientes y allegados, aunque conservó para sí 34800 libras nominales. ${ }^{24}$ Sin embargo, las cosas comenzaban a complicarse y el GOA continuaría con sus requerimientos de dinero más allá de lo obtenido por la emisión en debentures a 4.5 por ciento.

Para comprender cabalmente la situación financiera de la compañía volvamos un poco atrás. La primera asamblea de accionistas se llevó a cabo el 12 de diciembre de 1888, inmediatamente después de sellado el acuerdo entre J. S. Morgan \& Co. y Pellegrini para poner fin al conflicto suscitado por la sanción de la Ley 2379. En esa asamblea se leyó el informe de William Roberts del que resultaba que si bien la vía principal estaba en buen estado, aunque era necesario reemplazar alcantarillas y puentes provisorios, en cambio, el material rodante había sido recibido en muy mal estado, en especial las locomotoras, y su reparación había sido lenta porque los talleres estaban en construcción. Aunque ya habían sido puestas en condiciones de marcha 17 máquinas y algunos vagones, a fin de remediar la falta de material rodante y para cumplir la exigencia del gobierno debían adquirirse cuatro coches dormitorios, un coche oficial, uno de primera, cinco mixtos, cinco de segunda, 16 furgones, 100 vagones plataforma, 100 para hacienda, 200 cubiertos y diez locomotoras, todo lo cual demandaría por lo menos 130000 libras. Por eso se pedía autorización a la asamblea para emitir los debentures aconsejados por J. S. Morgan

\footnotetext{
${ }^{23}$ (8 de enero de 1889). Morgan Grenfell Papers (leg. 21795, vol. 4, f. 464). Guildhall Library. Londres, Inglaterra. Carta al secretario del Gran Oeste Argentino, Walter Helad.

${ }^{24}$ J. S. Morgan \& Co., en definitiva, acreditó en la cuenta del Gran Oeste Argentino 187500 libras de la siguiente manera: 22500 libras el 26 de febrero de 1889, 12500 libras el 15 de marzo, 15000 libras el 12 de abril, 30000 libras el 15 de abril, 27500 libras el 16 de mayo, 15000 libras el 7 de junio, 15000 libras el 15 de junio, 10000 libras el 2 de julio, 10000 libras el 10 de julio y 30000 libras el 13 de julio. Morgan Grenfell Papers (leg. 21769, vol. 25, f. 569). Guildhall Library. Londres, Inglaterra. El ferrocarril usó el dinero para hacer pagos a sus proveedores a través del London Joint Stock Bank. Morgan Grenfell Papers (leg. 21775, vol. 5, f. 222). Guildhall Library. Londres, Inglaterra. La casa Samuel B. Hale y Cía. adquirió 15000 libras nominales de los debentures (f. 173). Los títulos conservados por J. S. Morgan \& Co. constan en Morgan Grenfell Papers (leg. 21777, vol. 4, f. 102). Guildhall Library. Londres, Inglaterra. El sindicato estuvo formado por Abraham Mocatta \& Co. (50 000 libras), J. Capel \& Co. (50 000 libras), Greenwood \& Co. (35 000 libras), J. S. Morgan \& Co. (35 000 libras), Baring Brothers \& Co. (25 000 libras), Samuel B. Hale y Cía. (20 000 libras) y C. J. Hambro \& Co. (15 000 libras). Morgan Grenfell Papers (leg. 21793, vol. 1, f. 47). Guildhall Library, Londres, Inglaterra.
} 
\& Co. a los que se denominaría Equipment and improvement. La autorización que se dio fue por la suma de 500000 libras. Mientras tanto, la explotación era deficitaria. Para el ejercicio cerrado el 30 de junio de 1888 la pérdida había superado las 8000 libras. ${ }^{25} \mathrm{El}$ año siguiente no fue mejor. El nuevo material rodante, en su mayoría, se incorporó recién a fines de 1889. La línea sumó nuevos problemas: a la ya conocida mala calidad del agua que dañaba las calderas se agregó la escasez de carbón, producto de la interrupción de los servicios del FBAP por inundaciones. Se hicieron ensayos para extraer petróleo en Mendoza, pero el experimento no podía reemplazar fácilmente al combustible usual. La pérdida del valor de la moneda papel comenzaba a causar estragos. Los salarios aumentaron de 15 a 30\%, el precio de la leña (sustituto de más rápida obtención que el petróleo para el carbón) de 30 a 50\%. Mientras tanto el precio de los fletes permanecía igual. La pérdida al 30 de junio de 1889 se elevó a 12000 libras.

Era evidente que el futuro de la empresa dependía del pago puntual de la garantía por parte del gobierno argentino. Sólo así podría cumplir con los servicios de los debentures originales. También dependía de la obtención de más crédito para continuar con su plan de mejoras y hacer frente a las pérdidas de la explotación. Esta tarea había sido asumida por J. S. Morgan \& Co. pero pronto quedó en evidencia que las necesidades financieras del ferrocarril eran mayores que las originariamente previstas. Consumido el dinero proveniente de la venta de los debentures a $4.5 \%$ por 250000 libras nominales, J. S. Morgan \& Co. aceptó adelantar más dinero, esta vez recibiendo como garantía los mismos tipos de título, pero ahora tasados a 50\% de su valor nominal. Así se sucedieron cuatro préstamos: el 1 de agosto de 1889 por 32500 libras con vencimiento a un año e interés de 5\%; el 15 de agosto de 1889 por 50000 libras, en las mismas condiciones; el 21 de abril de 1890 por 12500 libras con interés de $6 \%$ a cuatro meses y el 24 de abril de 1890 por 5000 libras en las mismas condiciones que el anterior. ${ }^{26}$

Como resultado del convenio celebrado entre J. S. Morgan \& Co. y el vicepresidente Pellegrini, el Gran Oeste Argentino incorporó en 1889 diez locomotoras fabricadas por Beyer Peacock de Manchester que se sumaron a las 41 recibidas del Andino (en realidad sólo ingresaron en condiciones de uso o reparables 39) y a las seis incorporadas en 1887 y 1888 adquiridas con base en las primeras gestiones de Roberts. ${ }^{27}$

${ }^{25}$ (30 de junio de 1888). Annual Reports. Gran Oeste Argentino. Londres, Inglaterra.

${ }^{26}$ Morgan Grenfell Papers (leg. 21795, vol. 4, fs. 474 y 531; leg. 21769, vol. 25, fs. 458, 570, 574-576 y 580). Guildhall Library. Londres, Inglaterra. Para la operación más grande, la de 50000 libras, J. S. Morgan \& Co. obtuvo la participación de J. Capel \& Co. (20 000 libras) y de Greenwood \& Co. (otras 20000 libras).

${ }^{27}$ Información recopilada por Miguel Ángel Pignataro. Las seis locomotoras incorporadas en 1887 y 1888, fabricadas por Dübs y Sharp Stewart, parecen haber sido adquiridas de urgencia 


\section{LA CRISIS DE 1890 y COMPLETO CONTROL DEL GRAN OESTE ARGENTINO POR J. S. MORGAN \& CO.}

Para fines de 1889 la situación del Gran Oeste Argentino era precaria. No había podido equilibrar las cuentas. Se había visto obligado a endeudarse a fin de ampliar la dotación de locomotoras, coches y vagones. Había entrado en conflicto con las autoridades por razones del mal servicio. A todo ello se sumaba ahora la crisis económica que se desataría con furia en 1890 y que llevaría al gobierno argentino a dejar de cumplir sus obligaciones externas (entre ellas el pago de las garantías ferroviarias), ello produciría la caída de la casa Baring y depreciaría todos los títulos argentinos (López, 2000).

El ejercicio cerrado en junio de 1890 había dado peores resultados que los anteriores. La pérdida ascendía ahora a la enorme suma de 63469 libras. El directorio atribuía ello a no haber logrado autorización del gobierno para el adecuado incremento de tarifas por la continua depreciación del papel moneda, problema que se expone específicamente en López (2000, pp. 95-98) y Olarra (1968, p. 182). En enero se había autorizado un incremento del precio del transporte pero la suba del oro inmediata lo neutralizó. En julio, ya cerrado el ejercicio y días antes de la revolución del Parque, se autorizó otro aumento, pero el nuevo gobierno de Pellegrini lo dejó sin efecto poco después. ${ }^{28}$ Mientras tanto, la garantía había sido pagada hasta el 31 de diciembre de 1890, aunque en medio de rumores que indicaban lo contrario. Pero para finales de este año quedaba claro que, de ahí en adelante, en el mejor de los casos y por un tiempo prolongado, el pago de la garantía no se haría en efectivo sino mediante la entrega de títulos cuyo valor era incierto y su probabilidad de venta ínfima (véase López, 2000, pp. 471-477). Al comenzar 1891 era difícil imaginar una situación peor. J. S. Morgan \& Co. era acreedor del Gran Oeste Argentino y, además, mantenía en cartera una cantidad importante de títulos, otra cantidad no menos importante estaba en poder de los socios, casas y personas allegadas; y el ferrocarril no mostraba signos de recuperación. La opción era dejar de asistirlo financieramente y arriesgarse a su caída y a una pérdida enorme y definitiva o seguir apoyándolo y aumentar el riesgo con la esperanza de salvarlo. El no pago de la garantía, o su pago en títulos, significaba no poder cumplir con los servicios de los debentures y ello podía tener como resultado la liquidación. La responsabilidad de tomar una decisión

con base en existencias de esas fábricas y no construidas de acuerdo con las especificaciones del Gran Oeste Argentino. Respecto de los coches la cantidad incorporada en 1889 parece ser de 16. Información recopilada por Jorge Eduardo Waddell.

${ }^{28}$ (30 de junio de 1890). Annual Reports. Gran Oeste Argentino. Londres, Inglaterra. 
pareció exceder a los socios residentes en Londres, W. H. Burns y Robert Gordon. El 15 de enero de 1891 enviaron un telegrama al socio principal, John Pierpont Morgan, residente en Nueva York e hijo de Junius Spencer Morgan (fundador de la casa de Londres, que había fallecido en abril del año anterior) señalándole que el GOA debía al banco 60000 libras, ${ }^{29}$ que por garantía de la deuda había entregado 115000 libras debentures a 4.5\% que eran invendibles y que la explotación seguía siendo deficitaria. Morgan contestó que no tenía elementos de juicio para evaluar la situación del ferrocarril y dejaba en manos de la casa de Londres la decisión sobre el asunto. ${ }^{30}$ Burns y Gordon recibieron esta respuesta como un desafío y resolvieron imitar al propio John Pierpont Morgan, que en Estados Unidos se había especializado en hacerse cargo de compañías ferroviarias en problemas y reorganizarlas.

La mala situación financiera en la que se encontraban los hermanos Clark ayudó a Burns y Gordon a encontrar el camino para tomar un control más firme sobre el GOA e intentar alguna estrategia de recuperación. En abril de 1891, J. S. Morgan \& Co. adquirió 100000 libras en acciones preferidas que pertenecían a los hermanos Clark y que estos habían prendado a favor del banco. Con ellas J. S. Morgan \& Co. pasó a controlar efectivamente la compañía. En su nueva posición los socios de Londres decidieron reemplazar, cuando venciera su contrato a fin de año, al gerente general William Roberts, que no había logrado equilibrar las cuentas, y recomendaron a los directores residentes en Buenos Aires la búsqueda de un sucesor. ${ }^{31}$ Poco después Mateo Clark fue obligado, como un modo de poner fin a las cuentas pendientes entre los chilenos y el Gran Oeste Argentino, provenientes de la mala ejecución del contrato de mejoras, a entregar todas las acciones ordinarias que mantenía (20 000 por valor nominal de 400000 libras pero sin valor real en ese momento) al propio directorio ${ }^{32}$ Dentro del Gran Oeste Argentino no había ya rival para J. S. Morgan \& Co. La nueva situación no implicó más cambios formales que el retiro del directorio de Mateo Clark. Frederick William Lawrence siguió siendo el hombre del banco dentro del directorio pero sus otros componentes no eran personas que estuvieran dispuestas a enfrentarse a la entidad financiera. En Argentina, a principios de 1892, fue designado nuevo gerente general J. A. Villalonga y se agregó un vocal al directorio local:

${ }^{29}$ Las 60000 libras provenían de 32500 libras del primer préstamo, 10000 libras asumidas por J. S. Morgan \& Co. del segundo, 12500 libras del tercero y 5000 libras del cuarto. Véase nota 26.

${ }^{30}$ Morgan Grenfell Papers (leg. 21802, vol. 6, f. 103). Guildhall Library, Londres, Inglaterra.

${ }^{31}$ Morgan Grenfell Papers (leg. 21795, vol. 4, f. 723). Guildhall Library, Londres, Inglaterra.

${ }^{32}$ Lista de accionistas del 28 de diciembre de 1892. (28 de diciembre de 1892). Public Record Office (Dissolved Companies, compañía núm. 24345, Gran Oeste Argentino, caja 36158). Board of Trade 31. Londres, Inglaterra. 
T. R. Preston. ${ }^{33}$ El primero iba a ser responsable de volver a la empresa rentable, tarea en la que tuvo notable éxito; el segundo sería el encargado de gestionar ante el gobierno el aumento de tarifas y un arreglo por el tema de las garantías.

Era mucho lo que estaba en juego y, probablemente, el Banco tendría que seguir asistiendo financieramente al ferrocarril. Pero J. S. Morgan \& Co. se sentía firme. La caída de Baring había significado que fuera aquel el encargado de introducir a la plaza el empréstito moratoria que había resultado de lo aconsejado por el Comité Rothschild para salvar la situación argentina (López, 2000). Por otra parte, teniendo el control completo del GOA, llegados mejores momentos, podría imponer decisiones con las cuales obtener mayores beneficios respecto de sus tenencias. Tengamos en cuenta que por esta época, y dejando de lado la actividad especulativa consistente en comprar y vender buscando diferencias de cotización, J. S. Morgan \& Co. mantenía en cartera unas 10000 acciones preferidas por valor nominal de 200000 libras que le significaron una pérdida de 2755 libras en 1891 y de 13802 en 1892; también conservaba 18000 libras en debentures originales a 5\% que le causaron una pérdida de 1644 libras en 1891; por último, conservaba otras 18000 libras en debentures nuevos a 4.5\% que dieron una pérdida de 4379 libras en 1891 y de 1773 libras en 1892 . $^{34}$

Las acciones preferidas habían dejado de percibir dividendos en 1889. A los debentures originales (5\%) y para mejoras (4.5\%) se les comenzó a pagar los servicios en títulos de la moratoria argentina a mediados de 1891, tomados a la par. Un año después todo pago se suspendió (London Stock Exchange, 1894, p. 107). Esto llevó a un descenso continuo en las cotizaciones y a provocar las pérdidas mencionadas anteriormente. La única manera rápida de revertir esta caída era obtener un cambio de actitud del gobierno argentino respecto del pago de la garantía. Se hicieron múltiples gestiones, tanto en Londres como en Buenos Aires, pero sin resultado. En agosto de $1891 \mathrm{~J}$. S. Morgan \& Co. hizo una presentación quejándose por la permanencia de los interventores, figuras creadas por Juárez Celman. En carta a Nicholas Bouwer calificaba a esa idea de "grotesca" por interferir con la dirección de la compañía. ${ }^{35}$ Poco después, en octubre del mismo año, se llevaron adelante gestiones ante el ministro de Hacienda, Vicente Fidel López, y ante el enviado especial del gobierno argentino en Lon-

${ }^{33}$ Sobre la designación de Villalonga véase Morgan Grenfell Papers (leg. 21795, fs. 770, 814, 847, 892; leg. 21802, vol. 6, f. 122). Guildhall Library. Londres, Inglaterra. Sobre la designación de Preston véase (30 de junio de 1892). Annual Reports. Gran Oeste Argentino. Londres, Inglaterra.

${ }^{34}$ Morgan Grenfell Papers (leg. 21777, vol. 4, f. 103 y vol. 5, fs. 91 y 93). Guildhall Library, Londres, Inglaterra.

${ }^{35}$ Morgan Grenfell Papers (leg. 21795, vol. 4, f. 779). Guildhall Library, Londres, Inglaterra. 
dres, Victorino de la Plaza. ${ }^{36}$ La preocupación por el tema de la garantía se mantuvo presente en toda la correspondencia posterior, durante los años 1892 y $1893 .{ }^{37}$ En diciembre de 1892, a dos meses de haber asumido el nuevo gobierno el presidente Luis Sáenz Peña, el embajador argentino en Londres, Luis López Domínguez, anunció al banco que el ministro de Hacienda había resuelto fijar una suma anual tope para pagos al exterior, en reemplazo de la emisión de nueva deuda. Se pedía, en consecuencia, que se designara un representante para viajar a Buenos Aires a tratar el tema. La respuesta del banco, de acuerdo con su estilo, fue terminante: no aceptaría ninguna propuesta que significara apartarse de los compromisos asumidos. Además, agregaba que "J. S. Morgan \& Co. debe mantener su libertad de acción como agente financiero del GOA, que ha sido tratado en forma desconsiderada e injusta por las autoridades y que podría derivar en una acción judicial". ${ }^{38}$ Lo cierto es que en la cuestión de las garantías la política de Luis Sáenz Peña fue, en un principio, más desfavorable para las empresas que la de Pellegrini (López, 2000). Por este lado el GOA no tenía mucho que esperar por el momento.

Donde sí dieron resultados positivos las medidas de J. S. Morgan \& Co. fue en la explotación del ferrocarril. El nuevo gerente general redujo de manera extraordinaria los gastos de explotación. Ello, unido al cabo de breve tiempo a una recuperación de la actividad económica, permitió al GOA generar ganancias por primera vez. En el ejercicio cerrado el 30 de junio de 1891 hubo pérdidas pero de un monto muy inferior a las del año anterior: apenas 9000 libras. Entre los tráficos posibles, originados en Cuyo y con destino a Buenos Aires, comenzaba a destacarse el vino. Después de muchas gestiones, el gobierno había autorizado un aumento de tarifas. ${ }^{39}$ Para el ejercicio siguiente, el cerrado el 30 de junio de 1892, la mejoría se acentuó, sobre todo con base en el aumento del transporte de vino. Los gastos se redujeron a 125500 libras (incluidos los intereses de los bonos de conservación). En los años anteriores habían sido de 192000 libras, 209000 libras y 150 500, lo que muestra la eficacia inmediata de Villalonga. Los ingresos llegaron a 153000 libras, ligeramente superiores a los de los años anteriores, por lo que el superávit fue de 28500 libras. En el balance cerrado el 30 de junio de 1893, la situación se mantuvo lleganInglaterra.

${ }^{36}$ Morgan Grenfell Papers (leg. 21795, vol. 4, fs. 814, 847-848). Guildhall Library, Londres,

${ }_{37}^{37}$ Morgan Grenfell Papers (leg. 21795, vol. 4, fs. 883-949). Guildhall Library, Londres, Inglaterra.

38 (28 de diciembre de 1892). Morgan Grenfell Papers (leg. 21760.HC.4.1.7). Guildhall Library. Londres, Inglaterra. Correspondencia con la embajada argentina en Londres del 28 de diciembre de 1892.

39 (30 de junio de 1891). Annual Reports. Gran Oeste Argentino. Londres, Inglaterra. En los gastos se incluían los intereses de los debentures por mejoras y conservación, que ascendían a 20000 libras. Sin ellos el resultado ya habría sido positivo. 
do la ganancia a 27800 libras. El panorama, respecto del resultado de la explotación, era ahora prometedor. ${ }^{40}$

\section{EL ACUERDO POR RESCISIÓN DE LA GARANTÍA}

Si bien el ferrocarril no necesitaba incurrir en nuevas deudas, la falta de un acuerdo con el gobierno, por la cuestión de la garantía, significaba la imposibilidad de cumplir con los servicios de los debentures. Por un tiempo los tenedores de títulos no presionaron. Sin embargo, a principios de 1894, muchos de ellos estaban impacientes y comenzaron las tratativas con el directorio para alcanzar algún tipo de acuerdo.$^{41}$ Las negociaciones no fueron fáciles y en mayo, con el fin de evitar acciones legales, el GOA fue puesto bajo control de un administrador judicial (receiver).

Los tenedores de debentures, que habían formado un comité, mantuvieron por un tiempo su posición de no aceptar la propuesta del directorio, la que claramente no era muy generosa con ellos. Una asamblea extraordinaria del 19 de septiembre de 1894 dispuso la liquidación de la compañía. En esa situación fue recién cuando los debenturistas, ante el riesgo de pérdidas mayores, aceptaron la propuesta que fue aprobada judicialmente el 31 de octubre del mismo año. ${ }^{42}$ Por esta, el GOA declaraba que adeudaba 177750 libras por intereses de los 2370000 libras debentures originales a 5\% y 20212 libras por intereses de los 385000 libras debentures para mejoras a 4.5 por ciento.

Para hacer frente a todos ellos proponía la creación de 1700000 libras debentures de primer grado con un interés de 3\% hasta junio de 1895 y de 4\% de ahí en adelante y 1358250 libras debentures de segundo grado con un interés de $6 \%$, pero condicionando su pago a la existencia de ganancias y sólo exigibles después de cubiertos los servicios de los títulos anteriores. Los debentures preexistentes serían reemplazados por los nuevos títulos, a la par los originales a 5\% recibiendo sus tenedores la mitad en títulos de primer grado y la otra mitad en títulos de segundo grado; los debentures de mejoras a $4.5 \%$ serían canjeados a una tasa de $90 \%$ recibiendo $45 \%$ en

${ }^{40}$ (30 de junio de 1892 y 30 de junio de 1893). Annual Reports. Gran Oeste Argentino. Londres, Inglaterra.

${ }^{41}$ (16 de febrero de 1894). Morgan Grenfell Papers (leg. 21795, vol. 5, f. 105). Guildhall Library. Londres, Inglaterra.

${ }_{42}$ (27 de agosto de 1894). Morgan Grenfell Papers (leg. 21795, vol. 5, f. 158) y (30 de junio de 1894). Annual Reports. Gran Oeste Argentino. Londres, Inglaterra. 
títulos de primer grado y $45 \%$ en títulos de segundo grado. Los intereses atrasados serían pagados con debentures de primer grado. ${ }^{43}$

El GOA, mediante el acuerdo, no aumentaba el capital de su deuda en títulos, reducía la tasa de interés por ella y obtenía una condonación anticipada de intereses si no generaba utilidades. Además, salía de la situación de cesación de pagos en que se encontraba aun sin haber llegado a un acuerdo con el gobierno argentino por las garantías pendientes. Todo ello fue posible ejerciendo fuerte presión sobre los debenturistas para obligarlos a aceptar el acuerdo. Pero los resultados de la explotación seguían mejorando y ello también contribuía a vislumbrar un mejor futuro. Para el ejercicio cerrado el 30 de junio de 1894 el superávit llegó a 39000 libras y para el año siguiente a 96125 libras. Esta situación era producto de una esmerada administración y un espectacular aumento en el transporte de vino que obligó a incorporar 200 vagones cubiertos. Como resultado de la negociación con los debenturistas se sumó al directorio un nuevo miembro, Charles Marston Rose. ${ }^{44}$

Inmediatamente después de alcanzado el acuerdo por la deuda a $d e^{-}$ bentures, la posibilidad de solucionar el conflicto con el gobierno argentino por la garantía incumplida se hizo más cierta. Durante un tiempo se habló de que el gobierno ofrecería negociar su rescisión y el pago de los atrasos a cambio de la entrega de nuevos títulos públicos. Las compañías ferroviarias garantidas formaron un comité que pretendió negociar en conjunto. $\mathrm{Su}$ vicepresidencia fue ejercida por el presidente del GOA, George Russell. $\mathrm{Al}$ asumir la primera magistratura José Evaristo Uriburu, tras la renuncia de Luis Sáenz Peña en enero de 1895, el gobierno decidió impulsar las negociaciones, aunque con cada compañía por separado (López, 2000, pp. 485-493). En dichas negociaciones el GOA adoptó una de las posiciones más duras y obtuvo, en definitiva, mejores condiciones que las demás empresas. Tal como Carosso (1987) lo explica, esa posición fue posible ya que, a diferencia de la mayor parte de los ferrocarriles garantidos, el GOA podía ahora continuar su existencia sin la asistencia estatal; pero también se debió, en gran medida, a la forma en que J. S. Morgan \& Co. solía negociar con sus deudores (p. 407).

El Gran Oeste Argentino llegó, sin mayores dificultades, a acordar con el gobierno la suma de títulos a entregar para poner fin a la garantía. Sin embargo, un tema que generó la discordancia y demoró la concreción del

${ }^{43}$ Public Record Office (Dissolved Companies, compañía núm. 24345, Gran Oeste Argentino, caja 36158). Board of Trade 31. Londres, Inglaterra.

${ }_{44}$ (30 de junio de 1894 y 30 de junio de 1895). Annual Reports. Gran Oeste Argentino. Londres, Inglaterra. Sobre Rose véase George (1995, p. 26). Era hijo menor de Philip Rose, abogado de Baring y de Morgan y también del Gran Oeste Argentino. Por eso puede afirmarse que el nuevo director no era ajeno al círculo de J. S. Morgan \& Co. 
acuerdo fue la facultad de intervenir en las tarifas que el gobierno quería reservarse una vez concluida la garantía. Finalmente el GOA se salió con la suya y las autoridades renunciaron a esa facultad, salvo ganancias extraordinarias. Respecto de otras cinco empresas, con las que el gobierno también había acordado, la facultad de intervenir había subsistido. El contrato de rescisión se firmó en agosto de 1896 y fue aprobado por la Ley 3452 de diciembre de dicho año. En pago de lo adeudado, y como compensación de las garantías futuras, el GOA recibió cerca de 500000 libras (2 500000 pesos) en bonos del gobierno a $4 \%$ de interés. Se desistió de todo reclamo recíproco. El acuerdo llevó a su culminación el proceso de recuperación del GOA. Con base en la marcha de la empresa y a ese ingreso de fondos podían esperarse buenos tiempos para los accionistas y J. S. Morgan \& Co., el accionista más grande, se preocupó de que fueran mejores aun.

\section{J. S. MORgan \& Co. Y SUS Ganancias COMO aCCiOnista del Gran Oeste Argentino}

El directorio del Gran Oeste Argentino resolvió conservar los bonos del gobierno argentino, al menos en lo inmediato. Su valor de mercado era bajo y esta decisión debe considerarse acertada. Con ellos constituyó dos reservas: la primera, con las siete octavas partes de los títulos, estaba destinada a garantizar el pago de los intereses de los debentures de primer grado; la segunda, con el octavo restante, era una reserva general. Hecho esto podía disponerse de sumas para atender las necesidades de los accionistas pues los debenturistas tenían una buena garantía de sus intereses futuros. La compañía conservaba 20000 acciones ordinarias que habían sido devueltas por los hermanos Clark cuando resolvieron sus cuentas pendientes con el ferrocarril. Hasta entonces esas acciones habían carecido de valor, pero dados los resultados de los últimos ejercicios y la seguridad que recibían los debenturistas podía considerarse en colocarlas en el mercado a un precio razonable. El producto de la venta de estas acciones se destinaría, en primer lugar, al pago de los dividendos atrasados a las acciones preferidas, que por entonces importaban unas 100000 libras; el resto a reserva general. Con esta operación, J. S. Morgan \& Co. lograba, como accionista preferido, ingresar una suma importante por dividendos atrasados y, sobre todo, valorizar las acciones preferidas. También le daba valor a las ordinarias de las cuales poseía 5000 desde la constitución de la compañía y que había adquirido a los Clark. Además se anunciaba, y esto coronaba el procedimiento para valorizar las acciones, que se pagarían dividendos de $5 \%$ para ambas categorías de títulos, preferidas y ordinarias, con base en las utilidades que la línea venía dando. ¿Era prudente el camino seguido, 
o mostraba, en cambio, un derroche de fondos para un negocio a corto plazo? La respuesta no es concluyente. En esas circunstancias, si se tenía en cuenta el capital accionario y en bonos en circulación, el pago de dividendos e intereses en el futuro sería casi igual a las utilidades que venía generando la explotación más los servicios que pagaban los títulos del gobierno argentino (en total, alrededor de 170000 libras anuales).$^{45}$ Esta situación se reforzaba con el hecho de que la compañía había comenzado a constituir reservas que podían compensar los malos resultados de un año en particular.

La reserva general alcanzó las 136700 libras en 1898 con el saldo del producto de la venta de las 20000 acciones ordinarias. ${ }^{46}$ Pero había algunos puntos en contra. En primer lugar, los debentures de segundo grado, si la situación era próspera, debían pagar $6 \%$ de interés y eso era mucho. En segundo lugar, en caso de requerirse capital para mejoras o nuevas obras, que el creciente tráfico seguramente exigiría, deberían emitirse nuevos títulos. Tanto es así que ya en 1897 se había dispuesto rescatar los debentures de segundo grado por nuevos bonos a $4 \%$ pero pagando un premio de 12.5\%. También se había requerido autorización para emitir 150000 libras debentures más de primer grado para hacer frente a mejoras de la línea. Algunos accionistas expresaron su alarma por esta situación en la asamblea del 10 de noviembre de 1897. Se disponía de sumas líquidas para pagar dividendos y se emitían nuevos títulos de deuda. ${ }^{47}$

Lo cierto es que, a corto plazo, las ganancias obtenidas por J. S. Morgan \& Co. fueron impresionantes. La cotización de las acciones subió enormemente. Las preferidas, hasta fines de 1894, cuando no percibían dividendos, habían carecido de valor. A partir de entonces habían subido a 17 libras (sobre un valor nominal de 20 libras) para fines de 1895 y a 28 libras para fines de 1896. Este fue el precio máximo, producto del pago retroactivo de los dividendos atrasados de 5\% anual. El aumento del precio durante 1896 hizo anotar a J. S. Morgan \& Co. una ganancia de más de 120000 libras (tenía acciones por un valor nominal de 200000 libras). Sin embargo, no toda esa ganancia fue realizada, pues a fines de ese año todavía conservaba 7900 títulos (valor nominal en 158000 libras). Durante 1897 , y a pesar del dividendo ahora puntualmente pagado de $5 \%$, las

${ }^{45}$ Las utilidades fueron de 96000 libras en 1895, 130000 libras en 1896 y 165000 libras en 1897. Véase (30 de junio de 1895, 30 de junio de 1896, y 30 de junio de 1897). Annual Reports. Gran Oeste Argentino. Londres, Inglaterra.

${ }^{46}$ (30 de junio de 1898). Annual Reports. Gran Oeste Argentino. Londres, Inglaterra.

47 (30 de junio de 1897). Annual Reports. Gran Oeste Argentino. Londres, Inglaterra. 
acciones cayeron a 21 libras para fin de año. El banco tuvo que anotar una pérdida de 14800 libras. $^{48}$

Respecto de las acciones ordinarias, al ser puestas a la venta en enero de 1897, su precio fue de doce libras (es decir 60\% de su valor nominal). J. S. Morgan \& Co. suscribió 5750 y las vendió el mismo día a 13.5 libras realizando una ganancia de 8500 libras. $^{49}$

Los debentures también se valorizaron. Cuando fueron lanzados los nuevos títulos, después del acuerdo de octubre de 1894, los de primer grado cotizaban a 68 y los de segundo a 36 . Un año después habían subido a 99 y 96 y a fines de 1896 a 102 y 97, respectivamente. Inmediatamente después de la conversión, J. S. Morgan \& Co. comenzó a vender los títulos y realizó ganancias de 11000 libras a fines de 1894, 24700 libras a fines de 1895 y de 3500 libras durante $1896 .^{50}$

De alguna manera, J. S. Morgan \& Co. había podido completar la operación que se había propuesto cuando se convirtió en agente financiero de la compra de la prolongación del Ferrocarril Andino y adquirió los títulos que se crearon para el pago de su precio con el fin de mantener una parte de ellos, venderlos al cabo de un tiempo y embolsar una ganancia extra. Pero la demora había sido mucho mayor que la prevista. Una operación que tuvo que concluirse en uno o dos años duró diez y la casa bancaria debió invertir enorme cantidad de tiempo para alzarse con la ganancia.

\section{J. S. Morgan \& Co. pierde interés en el Gran Oeste Argentino}

Para fines de 1897 la actitud del banco respecto del ferrocarril comenzó a cambiar. El funcionamiento de la línea había dejado de ser una preocupación y el Gran Oeste Argentino empezó a convertirse para J. S. Morgan \& Co. en una empresa más respecto de la cual se podían comprar y vender títulos y ganar comisiones. Teniendo la convicción de que la línea era rentable, de que no había mayores conflictos con el gobierno y que, aun en malos años, los servicios de los debentures y razonables dividendos de las acciones podían ser pagados, ya no había justificación para inmiscuirse en sus asuntos. El hecho que puede ser entendido como la coronación del cambio de actitud de J. S. Morgan \& Co. se produjo el 31 de diciembre de 1897 cuando la tenencia de acciones preferidas que mantenía la casa ban-

${ }^{48}$ Morgan Grenfell Papers (leg. 21777, vol. 4, fs. 103-106). Guildhall Library. Londres, Inglaterra. El banco también especulaba a plazo más corto. En abril de 1895 había comprado acciones preferidas a 4.5\% y las fue vendiendo a precios muy superiores en los meses siguientes (vol. 6, f. 27).

${ }^{49}$ Morgan Grenfell Papers (leg. 21777, vol. 6, f. 26). Guildhall Library. Londres, Inglaterra. Inglaterra.

${ }^{50}$ Morgan Grenfell Papers (leg. 21777, vol. 6, fs. 94, 147 y 148). Guildhall Library. Londres, 
caria se repartió entre los socios. Quedaban por entonces 24700 acciones, a las que se asignó un valor de 132000 libras. J. P. Morgan recibió 75200 libras, los herederos del recientemente fallecido W. H. Burns 38200 libras y Robert Gordon 18600 libras. De ahí, sería cada socio, personalmente y no el banco, los que resolverían qué hacer con ellas. ${ }^{51}$

El de 1897 fue también un año de cambios, tanto para el banco como para el ferrocarril. En su transcurso fallecieron tres directores del GOA, entre ellos su presidente George Russell. También murió el presidente de la comisión local, Nicholas Bouwer. El nuevo presidente del directorio de Londres fue Frederick William Lawrence, socio asalariado de J. S. Morgan \& Co. En el banco, la muerte de W. H. Burns también afectó su organización. Robert Gordon se retiró, Frederick William Lawrence ascendió a socio general e ingresaron como nuevos socios los hijos de J. P. Morgan y de W. H. Burns, quienes se habían ocupado de los asuntos del GOA dentro de la casa bancaria; es decir, Burns y Gordon ya no estaban más. Lawrence nunca fue una persona que pesara en las decisiones; en realidad, el socio principal, J. P. Morgan, no quedó conforme con la nueva organización y comenzó la búsqueda de nuevos socios. En 1900 Frederick William Lawrence se retiró y con él desapareció el último vínculo personal con el Gran Oeste Argentino (Burk, 1989, pp. 57-58).

La operatoria normal de una casa bancaria como J. S. Morgan \& Co. giraba en torno a la cobranza de comisiones, de intereses por préstamos y a la especulación mediante la compraventa de valores. No era normal para ella controlar empresas e interesarse por su resultado. El caso del Gran Oeste Argentino, aunque no el único, había sido excepcional y producto de las circunstancias. En todos los demás casos en que el banco se interesó en empresas ferroviarias argentinas lo hizo con motivo de operaciones puntuales de compraventa de títulos, salvo, quizá, el Ferrocarril Trasandino con el cual mantuvo tenencias por bastante tiempo. Claro que este ferrocarril siempre tuvo una estrecha relación con el GOA, relación que no podemos describir en el espacio de este artículo.

A continuación mencionaremos, como prueba de lo dicho, una serie de típicas operaciones que J. S. Morgan \& Co. llevó a cabo por esta época con títulos valores de empresas ferroviarias argentinas: a) compraventa de 5000 debentures del Ferrocarril Córdoba y Rosario y 30000 libras en acciones del CA, entre el 14 y el 28 de octubre de 1892, donde ganó casi 3000 libras; b) compraventa de 1000 libras en acciones preferidas de los Ferrocarriles de Entre Ríos, entre el 29 de mayo y el 30 de noviembre de 1892, donde ganó algo más de 900 libras; c) la operación ya citada de compraventa de acciones ordinarias del GOA el 25 de enero de 1897, donde

${ }^{51}$ Morgan Grenfell Papers (leg. 21777, vol. 4, f. 106). Guildhall Library. Londres, Inglaterra. 
ganó exactamente 8539 libras; $d$ ) compraventa de acciones del FBAP por un valor de 100000 libras, entre el 1 de febrero de 1900 y el 31 de julio del mismo año, donde ganó 33000 libras. ${ }^{52}$ Todas estas fueron operaciones rápidas y rentables que es lo que el banco buscaba.

La modificación de la actitud de J. S. Morgan \& Co. respecto del Gran Oeste Argentino no significó el fin de la relación. El banco siguió manteniendo en cartera algunos de sus títulos y especuló con su compraventa. Además el ferrocarril siguió siendo cliente de J. S. Morgan \& Co. Como antes recordamos, el GOA había comenzado a acumular reservas: la que se formó con el saldo de la venta de las acciones ordinarias y los fondos para reparaciones y seguros. Esas reservas fueron invertidas en títulos y de estas inversiones se ocupó J. S. Morgan \& Co. Durante 1897, 1898 y 1899 invirtió sumas importantes, unas 70000 libras en títulos de ferrocarriles estadunidenses como Manhattan Railway, Milwaukee Electric, St. Louis Bridge, Georgia and Elgin East, Chesapeake and Ohio, Illinois Central, al mismo tiempo que vendía títulos del gobierno argentino que el GOA había recibido. ${ }^{53}$

También J. S. Morgan \& Co. siguió como el agente financiero del Gran Oeste Argentino para colocar sus nuevos títulos en el mercado de capitales, pero era un agente caro. En 1897 el costo para el GOA por el lanzamiento de debentures para mejoras fue de $4 \% .^{54}$ No es de extrañar entonces que el directorio del ferrocarril comenzara a cuestionar el monto de las comisiones. En julio de 1900 este consideraba ya innecesario pagar grandes comisiones para la colocación de sus títulos y en 1905 el banco debió aceptar una rebaja de 50\% de su comisión en el pago de intereses y dividendos..$^{55} \mathrm{El} \mathrm{GOA}$ se comportaba ya como una empresa autónoma. La absorción del Gran Oeste Argentino por el Ferrocarril Buenos Aires al Pacífico, poco después, significó el fin de la relación clientelar.

\section{CONCLusiones}

Algunas reflexiones finales merecen los hechos hasta aquí relatados. Entre 1887 y 1897 el GOA fue efectivamente controlado por J. S. Morgan \& Co. Aunque es cierto que la relación en esos diez años no fue homogénea y

\footnotetext{
${ }^{52}$ Morgan Grenfell Papers (leg. 21777, vol. 5, fs. 106, 100, 145; vol. 6, fs. 30 y 155; leg. 21793, vol. 2, f. 43). Guildhall Library. Londres, Inglaterra.

${ }_{53}$ Morgan Grenfell Papers (leg. 21775, vol. 8, f. 73). Guildhall Library, Londres, Inglaterra.

${ }^{54}$ (20 de mayo de 1897). Morgan Grenfell Papers (leg. 21760.H.C.1.7). Guildhall Library. Londres, Inglaterra.

${ }_{55}$ (12 de julio de 1900 y 16 de febrero de 1905). Morgan Grenfell Papers (leg. 21760.H.C.1.7). Guildhall Library. Londres, Inglaterra.
} 
que ese control fue más intenso a partir de 1891, el banco impuso su voluntad a la empresa ferroviaria durante todo este periodo y mantuvo una cantidad importante de acciones que reforzaba esa dominación.

Como anticipamos en la introducción, el caso descrito de control de una compañía ferroviaria por un banco, parece haber sido una excepción. No he encontrado en mis investigaciones anteriores, concerniente a compañías ferroviarias argentinas de capital británico (que actuaron en Argentina), otro caso semejante en el que una entidad financiera, u otra empresa de otro rubro, como la industria de material rodante o la producción de carbón mineral, haya designado representantes en el directorio o haya conservado por tan largo tiempo un porcentaje tan alto de acciones. Muy por el contrario, todas las empresas ferroviarias de capital británico mostraron una clara autonomía, preocupándose por obtener el mayor beneficio que podían lograr en la propia actividad y con un capital atomizado con múltiples accionistas, cada uno de los cuales era titular de una pequeña o mediana cantidad de acciones, con escasa presencia de grupos de inversión y sin que existieran mayorías que controlaban las asambleas. La atomización del capital ferroviario duró hasta el final de la presencia británica en los ferrocarriles de la Argentina en 1948 cuando fueron nacionalizados (López, 2004). Los directores de estas empresas eran, por su parte, profesionales de la actividad ferroviaria y muchos de ellos habían hecho carrera en las mismas compañías que luego condujeron. Es por ello que siempre hemos defendido la idea de que las empresas de ferrocarriles de capital británico fueron empresas autónomas, entendiendo por ello, en primer término, precisamente, que entre sus accionistas no había otras empresas de actividad distinta, o un grupo de ellas, que detentaran una mayoría controlante $y$, en segundo término, que su directorio permanecía en la medida que mantenía la confianza del amplio conjunto de los accionistas.

De la reconstrucción de hechos que ocupa la mayor parte de este artículo surge que el GOA, como dijimos, no siguió, al menos en los diez años analizados, esa línea general. Sin embargo, si repasamos las razones que llevaron a J. S. Morgan \& Co. a ese comportamiento anormal, creo que podemos afirmar que la excepción, en el fondo, no fue tal. En primer lugar, el hecho de que el GOA surgiera mediante la compra de una línea férrea prácticamente concluida obligó a reunir un enorme capital en poco tiempo. En esa tarea el compromiso de los miembros del sindicato pudo haber sido mayor que si se hubiera tratado de un ferrocarril que se instalaba y que requería del capital inicial a lo largo de un tiempo, dos años o más, durante el cual se iban produciendo los gastos de una construcción progresiva. Ello habría permitido volcar al mercado los títulos gradualmente: primero un porcentaje de los debentures, después la mitad de las acciones, más adelante el resto, todo ello en un plazo de dos o tres años. 
El GOA no fue así. Recordemos que en el sindicato, J. S. Morgan \& Co. y las casas vinculadas se comprometieron a colocar inmediatamente títulos por 900000 libras. La prudencia aconsejaba, en esos casos, quedarse con la mayor cantidad posible de valores para no saturar la plaza.

En segundo lugar, lo anterior se veía reforzado por el afán especulativo y al que ya nos hemos referido. Puesta la empresa en marcha, J. S. Morgan \& Co. mantuvo una gran cantidad de títulos, no sólo por la prudencia antes referida sino también porque esperaba hacer un buen negocio al cabo de un corto tiempo. En tercer lugar, el GOA tuvo grandes inconvenientes iniciales que desde Londres eran difíciles de prever. Esto frustró la especulación inicial. En este aspecto cabe señalar la intermediación inútil de los Clark. Ellos eran quienes debieron haber examinado la línea al adquirirla, los que debieron haber advertido los problemas del material rodante y, sin embargo, no sólo no tomaron medidas como emitir mayor capital e inmediatamente adquirir nuevas locomotoras, sino que cuando les tocó ejecutar las obras contratadas lo hicieron mal. Todo esto fue obligando a J. S. Morgan \& Co. a inmiscuirse cada vez más como lo muestra la discusión con Pellegrini. En cuarto y último lugar está la crisis de 1890. Fue por ella que el banco tomó control absoluto del GOA. Probablemente este último paso se dio porque J. P. Morgan en Estados Unidos venía haciendo cosas parecidas y porque los socios de Londres, Burns y Gordon, que también habían invertido personalmente en el ferrocarril, no quisieron ser menos. Si el GOA se hubiera constituido a comienzos de la década de 1880 es muy probable que su línea habría sido rentable en muy poco tiempo y que no habría necesitado contraer deudas como lo hizo. Además, la crisis llevó al Estado a no cumplir con la garantía y ello fue un duro golpe para el proyecto tal cual había sido concebido. En definitiva, consideramos que en este caso el hecho del control descrito, durante diez años, fue producto de las circunstancias y no una acción planeada de antemano. El negocio empezó a andar mal y, para protegerlo y enderezarlo, el banco pasó a desempeñar un papel que no había elegido ni al que estaba habituado. De otra manera tendría que haber aceptado una pérdida en sus números.

El control por J. S. Morgan \& Co. dejó huellas en el Gran Oeste Argentino. A él se debe una rápida mejora en la administración lograda mediante el reemplazo de Roberts por Villalonga. También la dureza con que discutió con el gobierno argentino, primero por las tarifas y el pago de la garantía, después por su rescisión. Dureza semejante se dio también en el trato del directorio con los poseedores de debentures. Presentó a ellos, perjudicados por la falta de pago de los servicios, una propuesta poco generosa y mantuvo la posición, aun con riesgo de causar la liquidación de la compañía. La dureza también puede verse en el hecho de que el ferrocarril logró elevar las tarifas, para equilibrar las cuentas, sin tener en 
cuenta cómo afectaba ello a la producción. Esto tuvo malas consecuencias en el futuro y la línea a Mendoza quedó como ejemplo de un ferrocarril que se despreocupaba de sus clientes. Además, el control por J. S. Morgan \& Co. dio a la empresa una característica peculiar: las decisiones fundamentales fueron tomadas por banqueros y no por profesionales de la actividad ferroviaria.

Sin embargo, el caso descrito es un buen ejemplo de cómo en la inversión ferroviaria en Argentina fueron más visibles los conflictos de intereses que el supuesto entramado de ellos del que han hablado las teorías dependentistas. No parece infundado afirmar que J. S. Morgan \& Co. usó su poder en el GOA para obtener beneficios a costa de otros inversionistas. Entre un agente financiero y un ferrocarril, normalmente, hubo siempre intereses contrapuestos, como en cualquier relación comercial, que resultaban de la posición que cada uno tomaba. El banco pretendía cobrar las mejores comisiones y, si podía, sacar alguna diferencia en el precio de los títulos, adquiriéndolos por un precio inferior al que los pensaba colocar. Si adelantaba dinero pretendía percibir el interés más alto posible. Pero todo ello estaba estipulado. Era esperable. En este sentido, el hecho de que J. S. Morgan \& Co. controlara al GOA por diez años permitió que siguiera llevándose altas comisiones e intereses por un tiempo mayor que el que normalmente habría correspondido. Pero esto no es verdaderamente importante. Lo que merece atención es discutir si J. S. Morgan \& Co., como poseedor de acciones preferidas, fundamentalmente, usó su poder para beneficiar a estas en perjuicio de los poseedores de debentures. Muchos de estos así lo creyeron y lo dijeron públicamente.

No puede negarse que, al final, las acciones preferidas fueron mejor tratadas que los debentures. Los poseedores de estos últimos fueron forzados por el directorio a aceptar un acuerdo en octubre de 1894 que significó en lo inmediato una quita, pues los intereses adeudados se pagaron en nuevos títulos de valor incierto y muy por debajo de la par y fueron obligados a canjear sus títulos originales por nuevos que en una mitad devengaban menores intereses y en la otra mitad veían condicionado su pago. En cambio, contra lo que podía esperarse ya que los debentures estaban en posición jurídica mejor en caso de dificultades, los poseedores de acciones preferidas a fines de 1896 percibieron íntegramente los dividendos adeudados y en dinero efectivo. ¿̇Fue ello premeditado por aquellos que como J. S. Morgan \& Co. tenían más acciones que debentures? Cuando en 1894, desde abril o mayo hasta octubre, se discutió el acuerdo con los debenturistas, todavía el gobierno argentino no había hecho ninguna oferta concreta para el arreglo de la garantía, pero se sabía que, tarde o temprano, ello ocurriría y significaría un ingreso de fondos para el GOA. Por lo menos eso era sabido por personas como George Russell o por los componentes de J. S. Morgan \& 
Co. Sin embargo, el directorio del GOA no mostró esta posibilidad a los tenedores de bonos y se negó a mejorar las condiciones que ofrecía y hasta especuló con la liquidación. Por la misma época, hubo cláusulas más generosas en los acuerdos con debenturistas en otras compañías ferroviarias.

Llegado el momento de pensar en las acciones, cuando ya el Estado había arreglado la cuestión de las garantías y los debenturistas aceptado el canje, no se les pidió a sus dueños que cedieran nada y se usó dinero proveniente de la venta de acciones ordinarias para pagar dividendos ¿ंFue justa esta decisión?, ¿̇no se estaba pagando dividendos con capital? La operación realizada fue hábil. Al destinar parte del producto de la venta de las acciones ordinarias a pagar dividendos atrasados de las preferidas se valorizaba a las propias acciones ordinarias porque ċqué dividendos podían esperar estas últimas si se adeudaba algo a las preferidas, que tenían el privilegio de ser acumulativas? Por último, es cierto que J. S. Morgan \& Co. ganó mucho con el pago de dividendos atrasados a las acciones preferidas, pero no parece que dicho pago obedeciera puramente a intereses egoístas e inmediatos de los accionistas. Se creía que también se estaba fortaleciendo a la compañía en sí. Prueba de ello es que J. S. Morgan \& Co. sólo vendió una pequeña parte de esas acciones y conservó el resto.

Es importante destacar, como ya lo recordamos antes, que cuando las acciones preferidas, y también las ordinarias, cobraron valor, J. S. Morgan \& Co. dejó de interesarse en las decisiones del GOA. Aunque las circunstancias personales contribuyeron a ello, en especial la desaparición y retiro de Burns y Gordon, nos parece que esta coincidencia muestra el significado de esta historia particular de los primeros años del GOA. Que el ferrocarril fuera controlado por un banco durante diez años no obedeció, como decíamos, a una estrategia diferente a la usual para canalizar inversiones ferroviarias a Argentina ni a una actitud diferente de J. S. Morgan \& Co. respecto de otros bancos de inversión o stockbrokers. El control fue producto, como ya lo anticipamos, de algunos hechos inesperados que obligaron a J. S. Morgan \& Co. a actuar de manera diferente para proteger su inversión y no a una planeada excepción a la operatoria corriente. Una vez que el plan inicial se hubo concretado y el banco obtuvo su ganancia con las comisiones y las diferencias de cotización, J. S. Morgan \& Co. dejó que la empresa ferroviaria se manejara libremente.

Por último, creemos oportuno señalar que el relato anterior sirve para comprender mejor cómo se llevó a cabo la inversión de capitales de personas residentes en Gran Bretaña en la actividad ferroviaria de un país lejano como lo era Argentina, sobre todo en lo referente a nuevas empresas que iniciaban su actividad. Quien tenía en sus manos un negocio ferroviario viable, un promotor que había logrado obtener una concesión del gobierno argentino, tenía la necesidad de vincularse con un agente financiero 
con una cartera de clientes en Londres, es decir un banco de inversión, o un agente de bolsa. Muchas veces, ese concesionario no tenía por sí esas vinculaciones y recurría a otro intermediario. Los hermanos Clark, como vimos, habían perdido las que habían logrado en un negocio anterior y recurrieron para el caso del GOA a una persona extravagante como Charles Henry Sanford. Cuantos más intermediarios existían, la inversión corría el riesgo de hacerse en forma menos eficiente. Una vez aceptada la participación por el agente financiero este pasaba a desempeñar, al menos por un tiempo, un papel preponderante: organizaba la compañía a registrar y la composición de su capital y, finalmente, llevaba los pasos necesarios para su suscripción. Esto implicaba realizar un paso intermedio que era la constitución del sindicato de agentes financieros. Un número de ellos se comprometía a colocar cada uno una cantidad de títulos. Difícilmente un banco de inversión por sí solo estaba en condiciones de llevar adelante la suscripción.

Como último paso, cada agente financiero debía convencer a sus clientes de que volcaran su capital en la nueva empresa. Una vez logrado ello, la función del sindicato cesaba y el capital quedaba repartido entre una multitud de pequeños y medianos ahorristas. Por supuesto que esto último podía demorarse si los agentes financieros resolvían quedarse ellos mismos con una cantidad de títulos para especular con la suba de su cotización. Después de todo, comprar y vender títulos era una actividad cotidiana de estas instituciones. La retención de títulos en cartera, como toda especulación, podía ser peligrosa, como resultó ser en el caso del GOA y como la quiebra de Baring en 1890 lo mostró con toda su crudeza.

Lo que nos parece claro, como el caso descrito y de muchos otros similares, es que los bancos de inversión londinenses no veían esta actividad como algo que iba más allá de un procedimiento para cobrar comisiones, percibir sumas importantes por diferencias en los precios de compraventa y un mecanismo para mantener activa su cartera de clientes. Podía ocurrir que, en algún caso como el presente, llegaran a realizar una actividad adicional, como la de colocarse al frente de una empresa de transporte, pero ello era circunstancial. Ello estaba fuera de sus expectativas, de su actividad específica y de los intereses por los que actuaban.

\section{LISTA DE REFERENCIAS}

Burk, K. (1989). Morgan Grenfell, 1845-1888. The biography of a merchant bank. Oxford: Oxford University Press.

Carosso, V. P. (1987). The Morgan: Private international bankers. 1854-1913. Massachussets: Harvard University Press. 
George, A. (1995). A history of Norton Rose. Chesterton: Granta.

LONDON STOCK ExCHANGE (1894). Yearbook 1893. Londres, Inglaterra.

López, M. J. (1991). Historia de los ferrocarriles de la provincia de Buenos Aires. 1857-1886. Buenos Aires: Lumiére.

LÓPez, M. J. (2000). Ferrocarriles, deuda y crisis. Historia de los ferrocarriles en la Argentina de 1887 a 1896. Buenos Aires: Belgrano.

LóPEz, M.J. (2004). Ganancias y pérdidas de los inversores en la venta de las empresas ferroviarias británicas en 1947. XIX Jornadas de Historia Económica. San Martín de los Andes: Sociedad Argentina de Historia Económica.

Mabragaña, H. (ca. 1910). Los mensajes: historia del desenvolvimiento de la nación Argentina redactada cronológicamente por sus gobernantes. 1810-1910(t. 4). Buenos Aires: Talleres Gráficos de la Compañía Nacional de Fósforos.

Olarra, J. R. (1968). Evolución monetaria argentina. Buenos Aires: Eudeba.

República Argentina, Ministerio de Obras Públicas (1902). Leyes, contratos y resoluciones referentes a ferrocarriles y tranvías a tracción mecánica de la República Argentina (t. 4). Buenos Aires: Taller Tipográfico de la Penitenciaría Nacional.

\section{Bibliografía}

LóPEz, M. J. (1994). Historia de los ferrocarriles nacionales. 1866-1886. Buenos Aires: Editorial Lumière.

López, M. J. (marzo, 1996). La quiebra de los hermanos Clark. En Todo es Historia, 344. 